\title{
Experimental Evidence of Long-Lived Electric Fields of Ionic Liquid Bilayers
}

\author{
Mattia Belotti ${ }^{\mathrm{a}}$, Xin Lyu ${ }^{\mathrm{a}}$, Longkun Xu ${ }^{\mathrm{b}}$, Peter Halat ${ }^{\mathrm{c}}$, Nadim Darwish ${ }^{\mathrm{a}}$, Debbie S. Silvester ${ }^{\mathrm{a}}$, \\ Ching Goh ${ }^{\mathrm{a}}$, Ekaterina I. Izgorodina*,c ${ }^{*}$ Michelle L. Coote*,b and Simone Ciampi*,a
}

${ }^{a}$ School of Molecular and Life Sciences, Curtin University, Bentley, Western Australia 6102, Australia; Email: simone.ciampi@curtin.edu.au

${ }^{\mathrm{b}}$ ARC Centre of Excellence for Electromaterials Science, Research School of Chemistry, Australian National University, Canberra, Australian Capital Territory 2601, Australia; Email: michelle.coote@anu.edu.au 'School of Chemistry, Monash University, Clayton, Victoria 3800, Australia; Email: katya.pas@monash.edu

S1. Supplementary Experimental and Computational Results 


\section{S1. Supplementary Experimental and Computational Results}

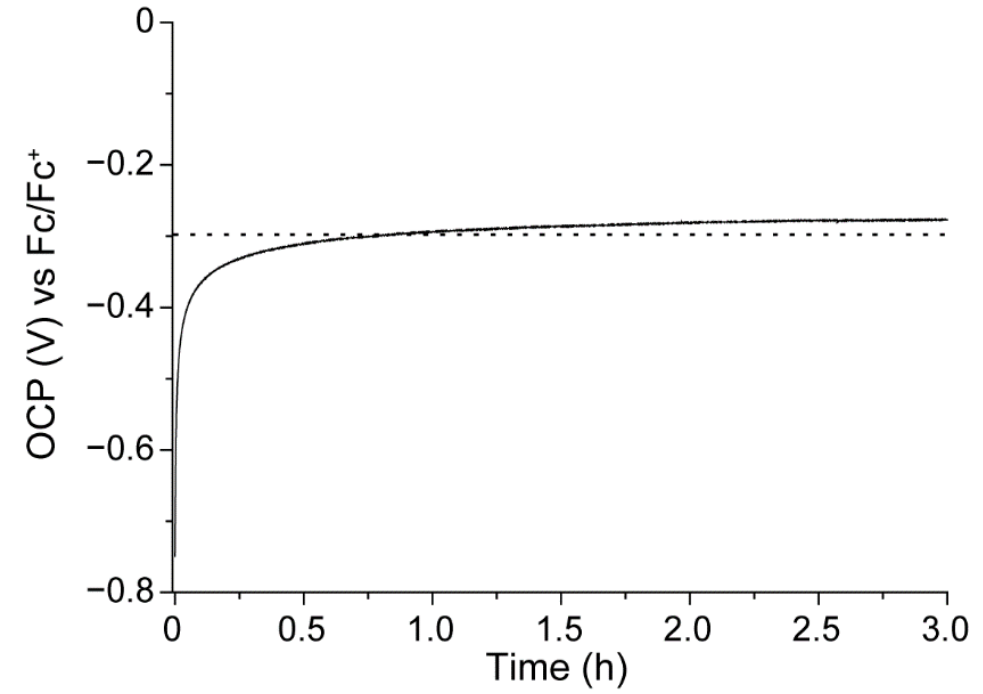

Figure S1. Representative OCP-time measurement acquired with a platinum electrode immersed in [EMIM] [EtSO 4 ]. The OCP measurement began immediately after a $60 \mathrm{~s}$ negative pulse $(-1.0 \mathrm{~V}$ relative to the system's initial OCP $)$. The dotted horizontal line indicates the OCP prior to the pulse. The electrode's OCP relaxes asymptotically. 


\section{a)}

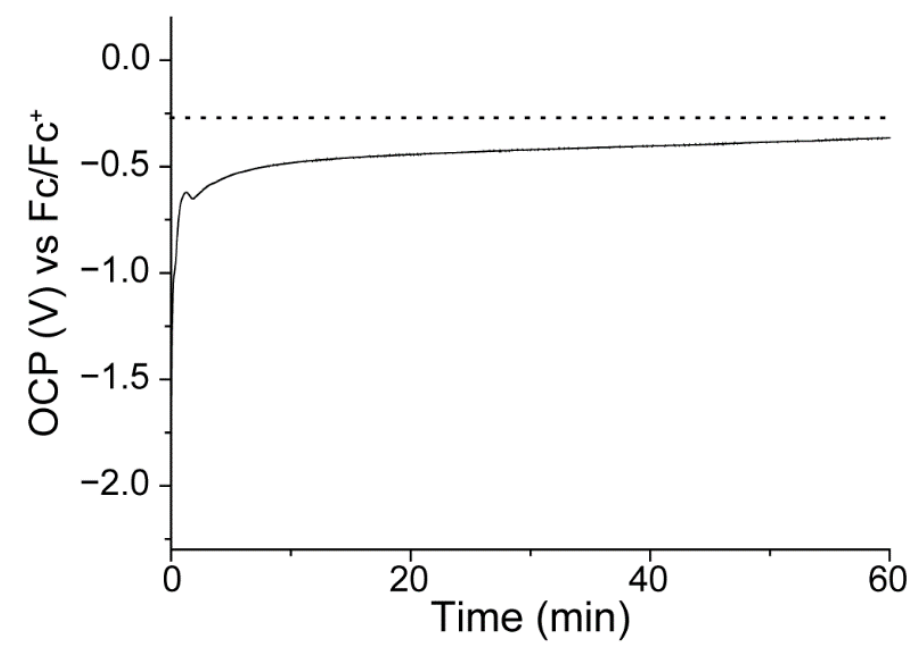

b)

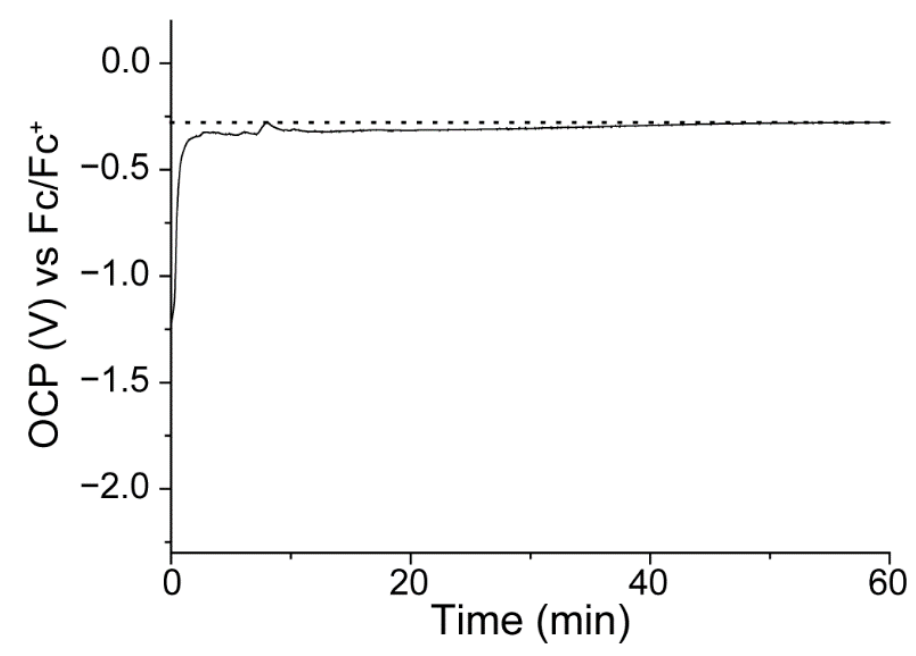

Figure S2. Representative OCP-time measurements acquired with platinum electrodes immersed in acetonitrile containing either (a) $0.1 \mathrm{M}$ (a), or (b) $0.5 \mathrm{M} \mathrm{Bu}_{4} \mathrm{NClO}_{4}$. The recording of OCP versus time started after a $60 \mathrm{~s}$ negative pulse $(-2.0 \mathrm{~V}$ from the initial OCP). The dotted horizontal line indicates the initial OCP (recorded prior to the pulse). In contrast to the OCP relaxation experiments performed with RTILs, molecular solvent/electrolyte systems did not show discrete OCP plateaus. 


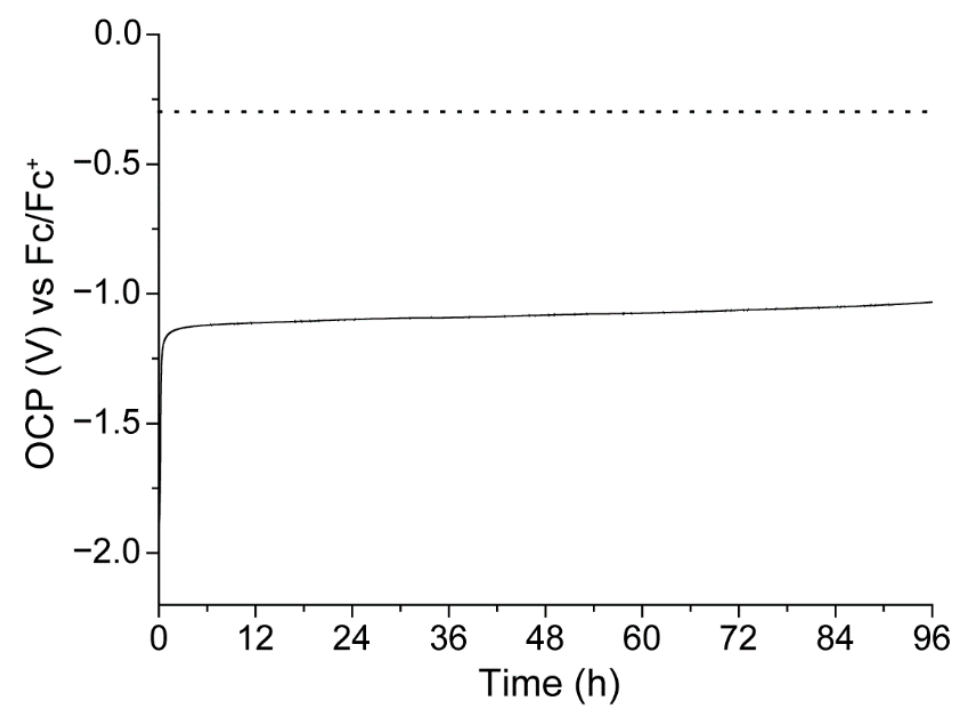

Figure S3. OCP-time measurement acquired with a platinum electrode immersed in $[\mathrm{EMIM}]\left[\mathrm{EtSO}_{4}\right]$. The OCP measurement began immediately after a $60 \mathrm{~s}$ negative pulse $(-2.0$ $\mathrm{V}$ relative to the system's initial OCP). The dotted horizontal line indicates the OCP prior to the pulse. The negative bias excursion led to an exceedingly stable OCP plateau, located around $-1.10 \mathrm{~V}$, which lasted at least 96 hours. 


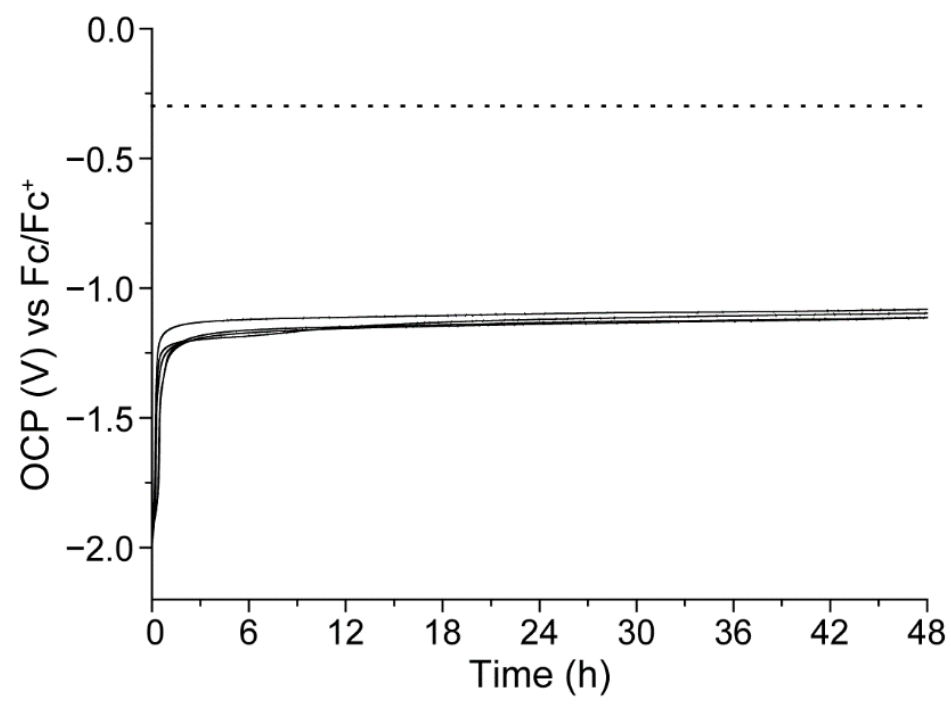

Figure S4. OCP-time measurements acquired with a platinum electrode immersed in [EMIM][EtSO $]$. The OCP measurement began immediately after a $60 \mathrm{~s}$ negative pulse $(-2.0$ $\mathrm{V}$ relative to the system's initial OCP). The dotted horizontal line indicates the average OCP prior to the pulse. The negative bias excursion led to OCP plateaus located around between $-1.13 \mathrm{~V}$ and $-1.25 \mathrm{~V}$ that lasted at least 48 hours. 


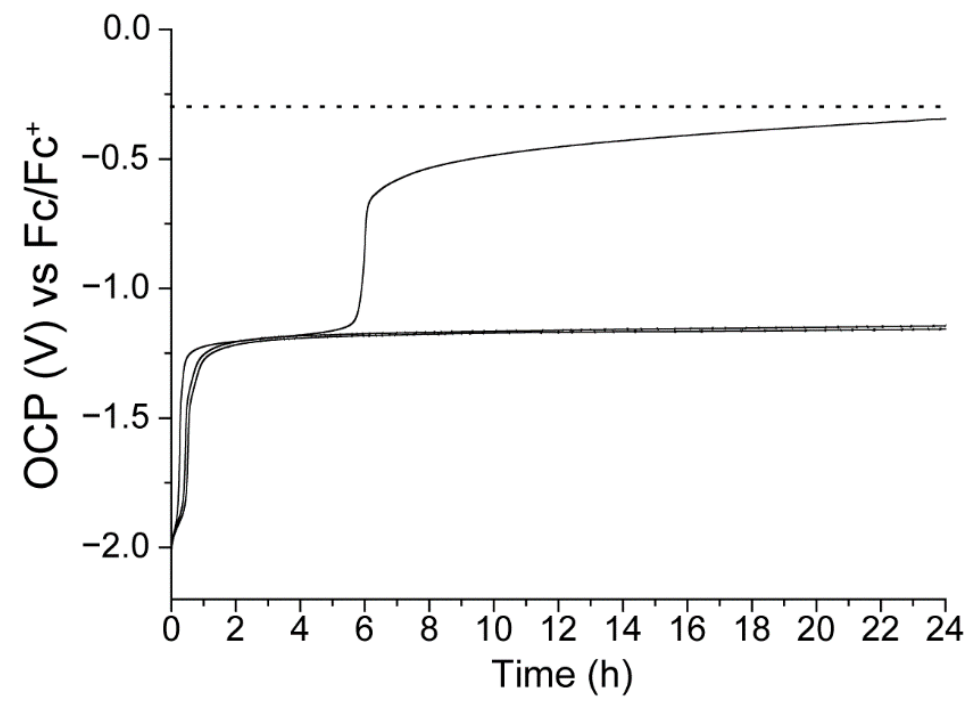

Figure S5. OCP-time measurements acquired with a platinum electrode immersed in $[\mathrm{EMIM}]\left[\mathrm{EtSO}_{4}\right]$. The OCP measurement began immediately after a $60 \mathrm{~s}$ negative pulse $(-2.0$ $\mathrm{V}$ relative to the system's initial OCP). The dotted horizontal line indicates the average OCP prior to the pulse. The negative bias excursion led to OCP plateaus located around $-1.25 \mathrm{~V}$ that lasted between 6 and 24 hours. 
a)

b)
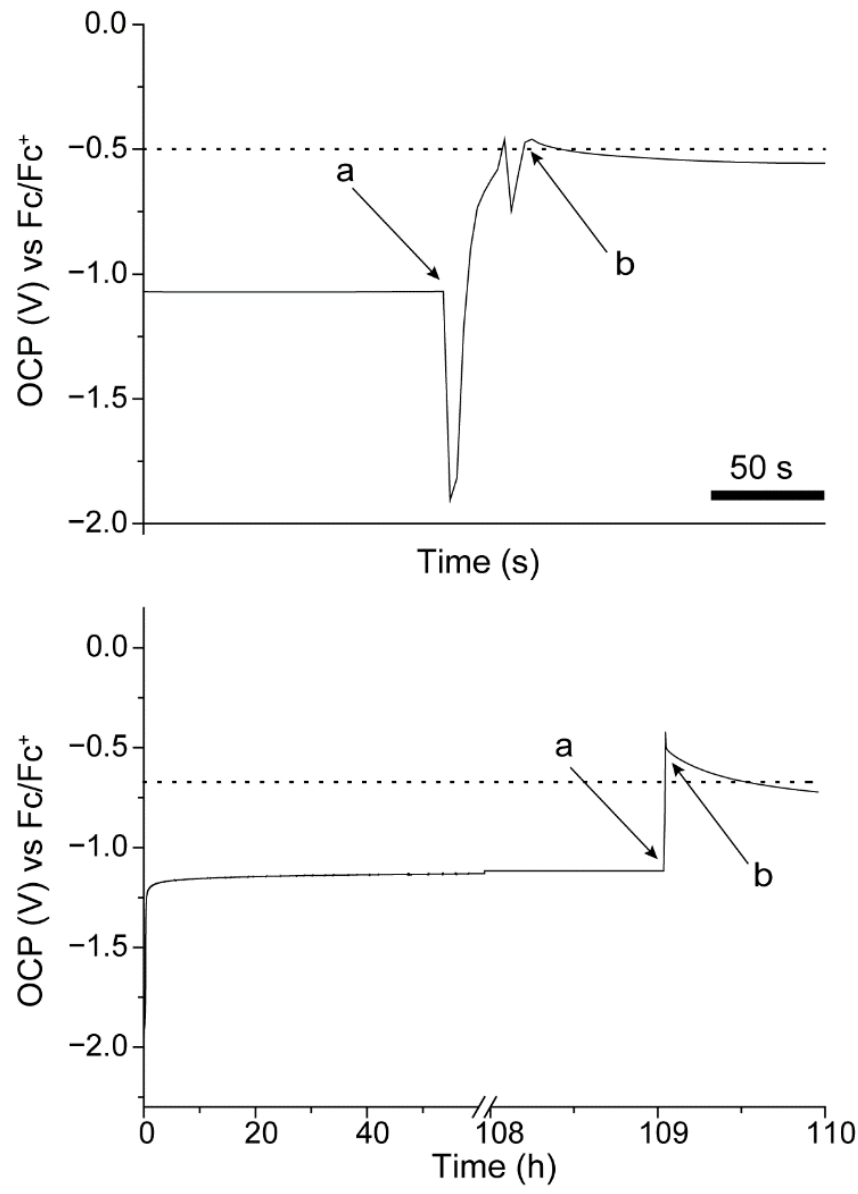

Figure S6. Representative OCP-time data showing how the stable OCP plateau, indicative of the overscreened dipolar layer formed on a platinum electrode in [EMIM][EtSO 4 ] after a cathodic pulse, is being lost after mechanical shaking. The leftmost portion of the OCP traces shown here are data recorded approximately either $24 \mathrm{~h}$ (a) or $109 \mathrm{~h}$ (b) after the end of the $60 \mathrm{~s}$ cathodic pulse $(-2.0 \mathrm{~V}$ relative to the system's initial OCP). The dotted horizontal lines represent the initial OCP prior to the pulse. Mechanical shaking of the electrode, while this was held under nitrogen over the liquid sample (point marked as "a"), disrupted the ordered RTIL structure, as indicated by a sharp positive shift of the electrode's OCP back towards its initial rest value once this is re-immersed in the RTIL sample (point marked as " $b$ "). 
a)

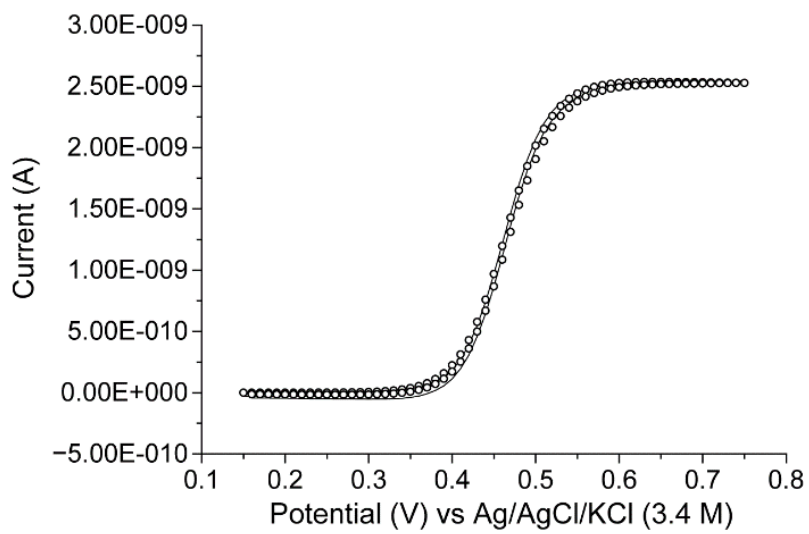

b)

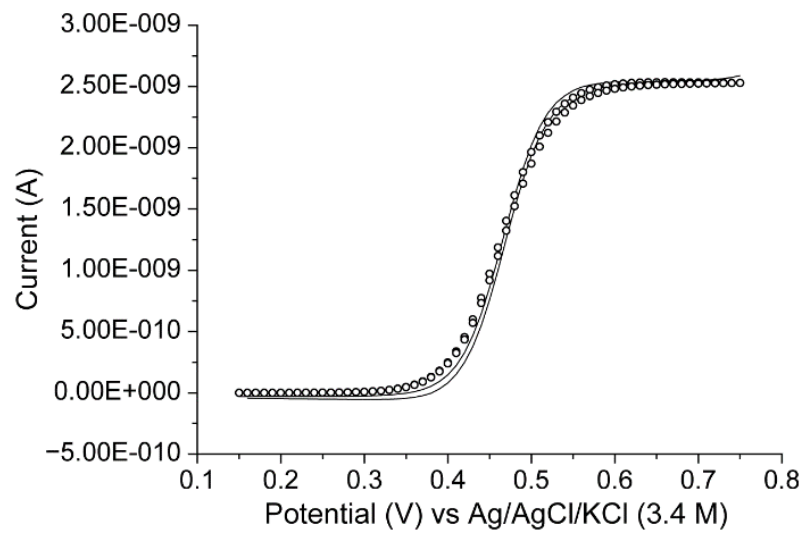

Figure S7. Voltammograms $\left(50 \mathrm{mV} \mathrm{s}{ }^{-1}\right)$ for the oxidation of ferrocene $\left(5.5 \times 10^{-4} \mathrm{M}\right.$ ferrocene in acetonitrile with $2.5 \times 10^{-2} \mathrm{M}$ of $\mathrm{Bu}_{4} \mathrm{NPF}_{6}$ ) obtained on a platinum microdisk electrode (nominal radius of $5 \mu \mathrm{m}$ ) prior (a) and after (b) its immersion and removal from a [EMIM][EtSO 4 ] sample. The electrode, while in the RTIL sample, was biased for $60 \mathrm{~s}$ at $-2.0 \mathrm{~V}$ (relative to the system's initial OCP). The experimental and simulated curves are plotted as solid lines and empty symbols, respectively. The standard deviation between experiments and simulations was less than 0.01 . There is no evidence of changes to the electrode active area $\left(9.85 \times 10^{-7} \mathrm{~cm}^{2}\right)$ after the cathodic pulse. 


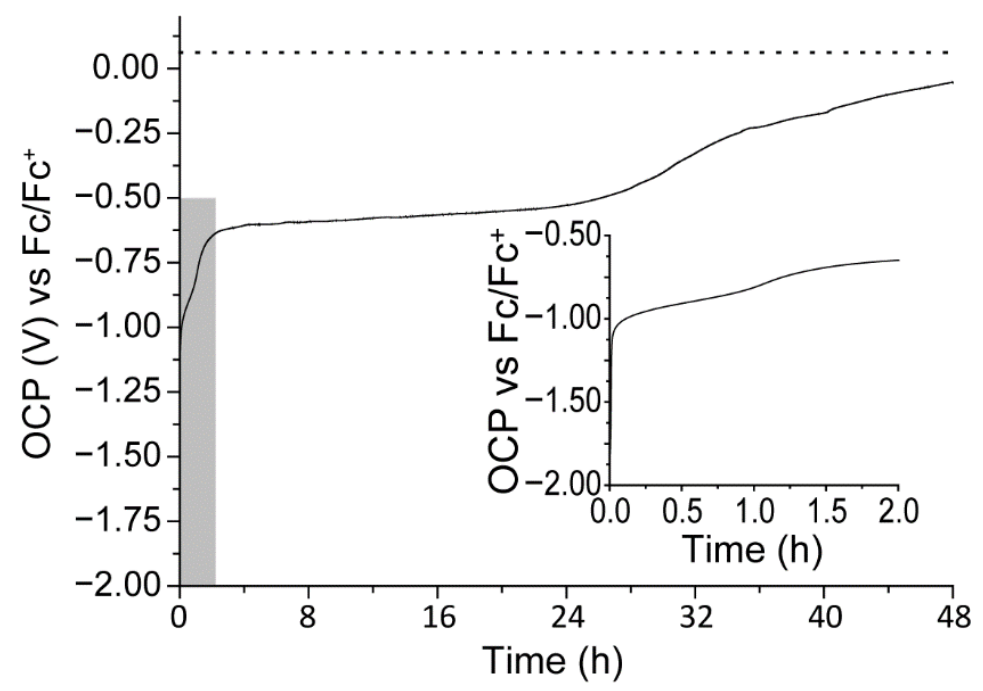

Figure S8. Representative OCP-time measurement acquired with a platinum electrode immersed in [EMIM][BF4], after the application of a $-2.0 \mathrm{~V}$ potential pulse away (cathodically) from the system's initial OCP. The pulse lasted 60 seconds. The grey shaded area in indicates the data plotted as figure inset, which highlight the onset of crowding in $[\mathrm{EMIM}]\left[\mathrm{BF}_{4}\right]$, as an OCP horizontal step located around $-1.0 \mathrm{~V}$. The overscreening OCP signature of the platinum/[EMIM] $\left[\mathrm{BF}_{4}\right]$ system is found around $-0.62 \mathrm{~V}$. The dotted horizontal line represents the initial OCP prior to the pulse. 


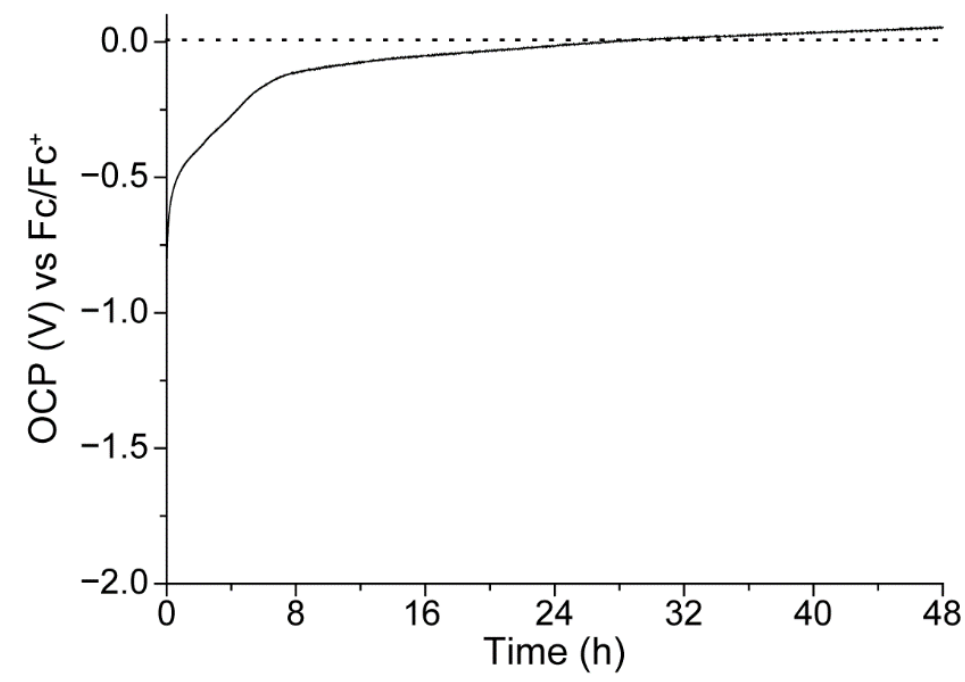

Figure S9. Representative OCP-time measurement acquired with a platinum electrode immersed in [HMIM] $\left[\mathrm{PF}_{6}\right]$. The electrode OCP recording started immediately after a $360 \mathrm{~s}$ cathodic pulse $(-2.0 \mathrm{~V}$ relative to the system's initial OCP). The dotted horizontal line represents the initial OCP prior to the pulse. 


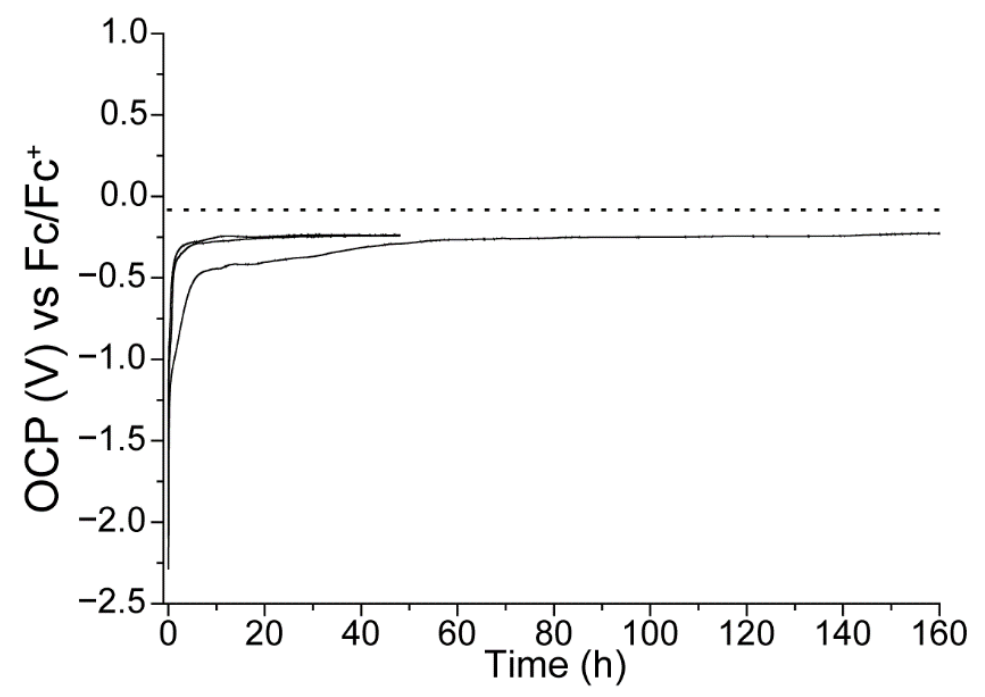

Figure S10. Representative OCP-time measurements acquired with platinum electrodes immersed in [BMPyrr][NTf 2 . The OCP measurement began immediately after the end of a $60 \mathrm{~s}$ cathodic potential step $(-2.0 \mathrm{~V}$ relative to the system's initial OCP). The dotted horizontal line marks the average initial OCP prior to the pulse. 


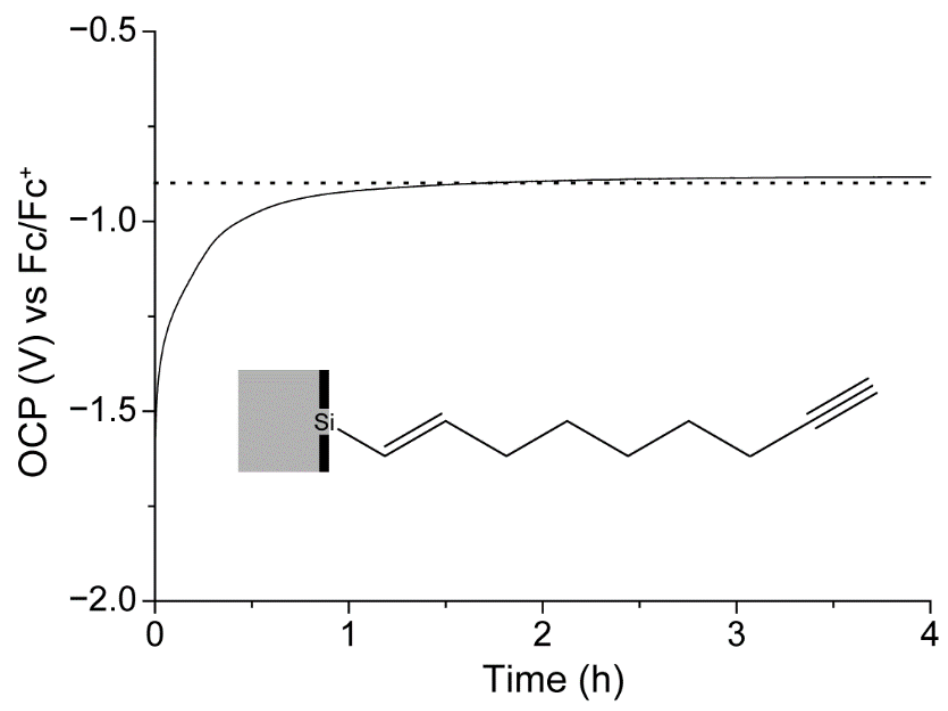

Figure S11. Representative OCP-time measurement acquired on a monolayer-modified silicon electrode immersed in [EMIM] [EtSO 4$]$. The electrode was coated with a Si-C-bound monolayer prepared by grafting 1,8-nonadiyne on hydrogen-terminated $\mathrm{Si}(111)$. The electrode OCP recording started immediately after a $60 \mathrm{~s}$ cathodic pulse $(-2.0 \mathrm{~V}$ relative to the system's initial OCP). The dotted horizontal line marks the OCP prior to the cathodic pulse. 


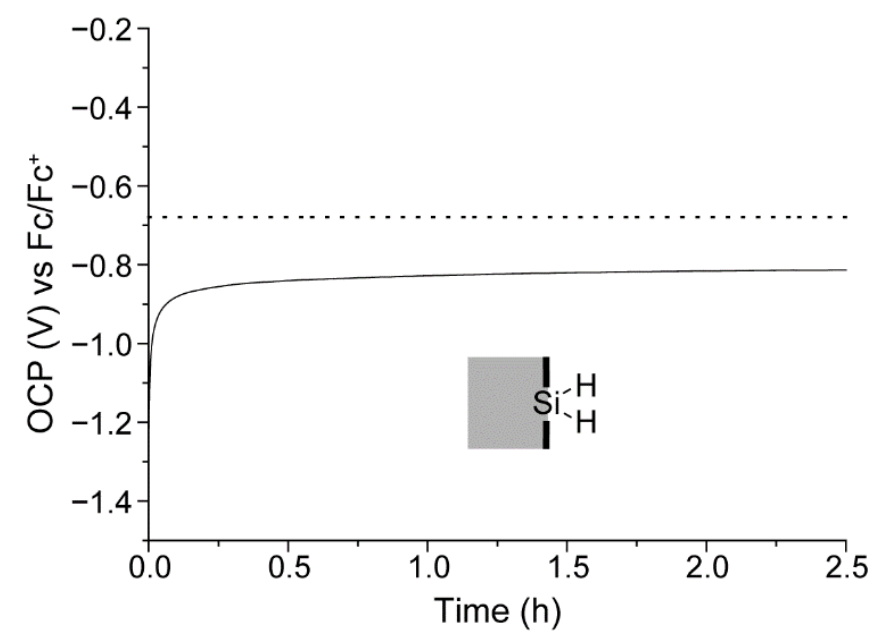

Figure S12. Representative OCP-time measurement acquired on a hydrogen-terminated $\mathrm{Si}(111)$ electrode in [EMIM][EtSO 4$]$. The recording of the electrode's OCP started immediately after a $60 \mathrm{~s}$ cathodic pulse $(-2.0 \mathrm{~V}$ relative to the system's initial OCP $)$. The dotted horizontal line marks the OCP prior to the cathodic pulse. The OCP after the pulse asymptotically relaxed back towards its initial value, but never reached it. The cathodic shift of the final OCP is indicative of a degree of surface corrosion, which is expected given the lack of chemical passivation of the hydride surface (see Figure S11 for a comparison with a chemically passivated Si surface). 


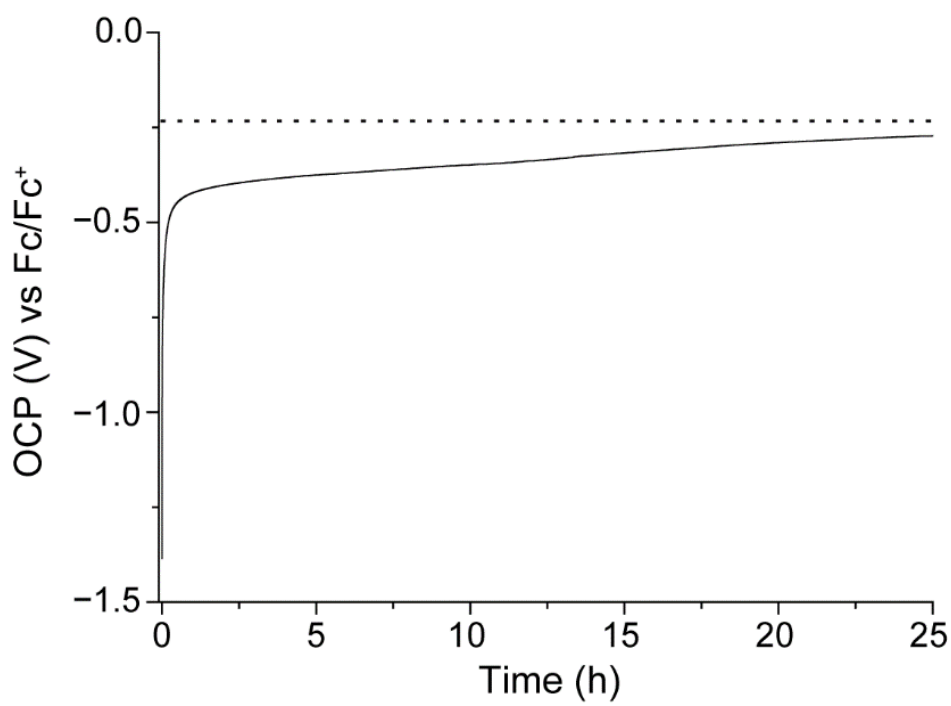

Figure S13. Representative OCP-time measurement acquired with a carbon plate working electrode and a platinum counter immersed in [EMIM][EtSO $]$. The electrode OCP recording started immediately after a $60 \mathrm{~s}$ cathodic pulse $(-2.0 \mathrm{~V}$ relative to the system's initial OCP). The dotted horizontal line represents the initial OCP prior to the pulse. 


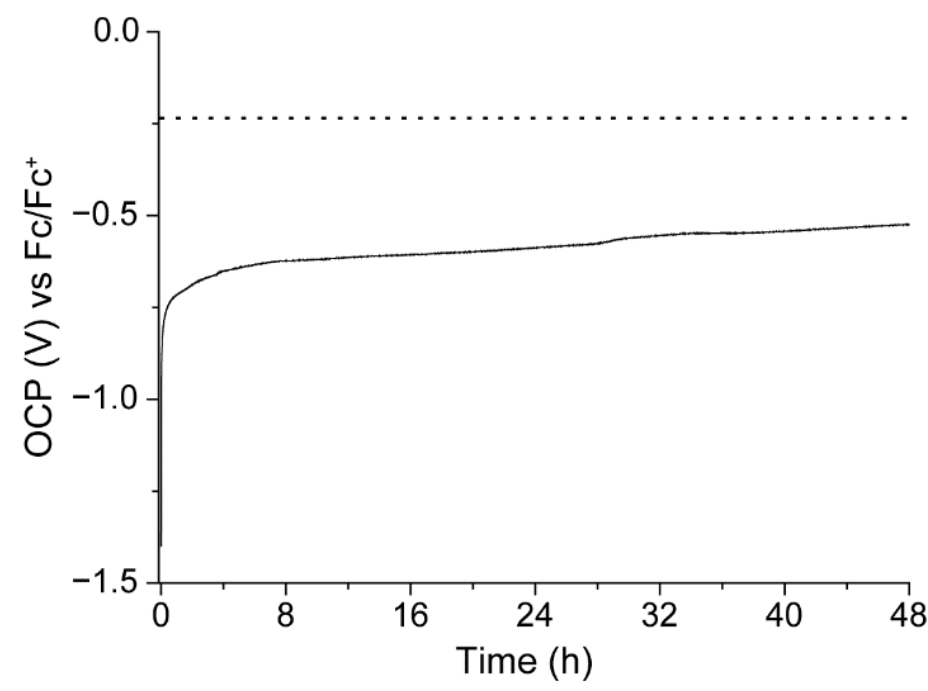

Figure S14. Representative OCP-time measurements acquired with a gold wire working electrode and a platinum counter immersed in [EMIM][EtSO 4$]$. The electrode OCP recording started immediately after a $60 \mathrm{~s}$ cathodic pulse $(-2.0 \mathrm{~V}$ relative to the system's initial OCP). Dotted horizontal lines represent the average initial OCP. Negative bias excursions lead to very stable OCP plateaus located between $-0.6 \mathrm{~V}$ and $-0.8 \mathrm{~V}$. 

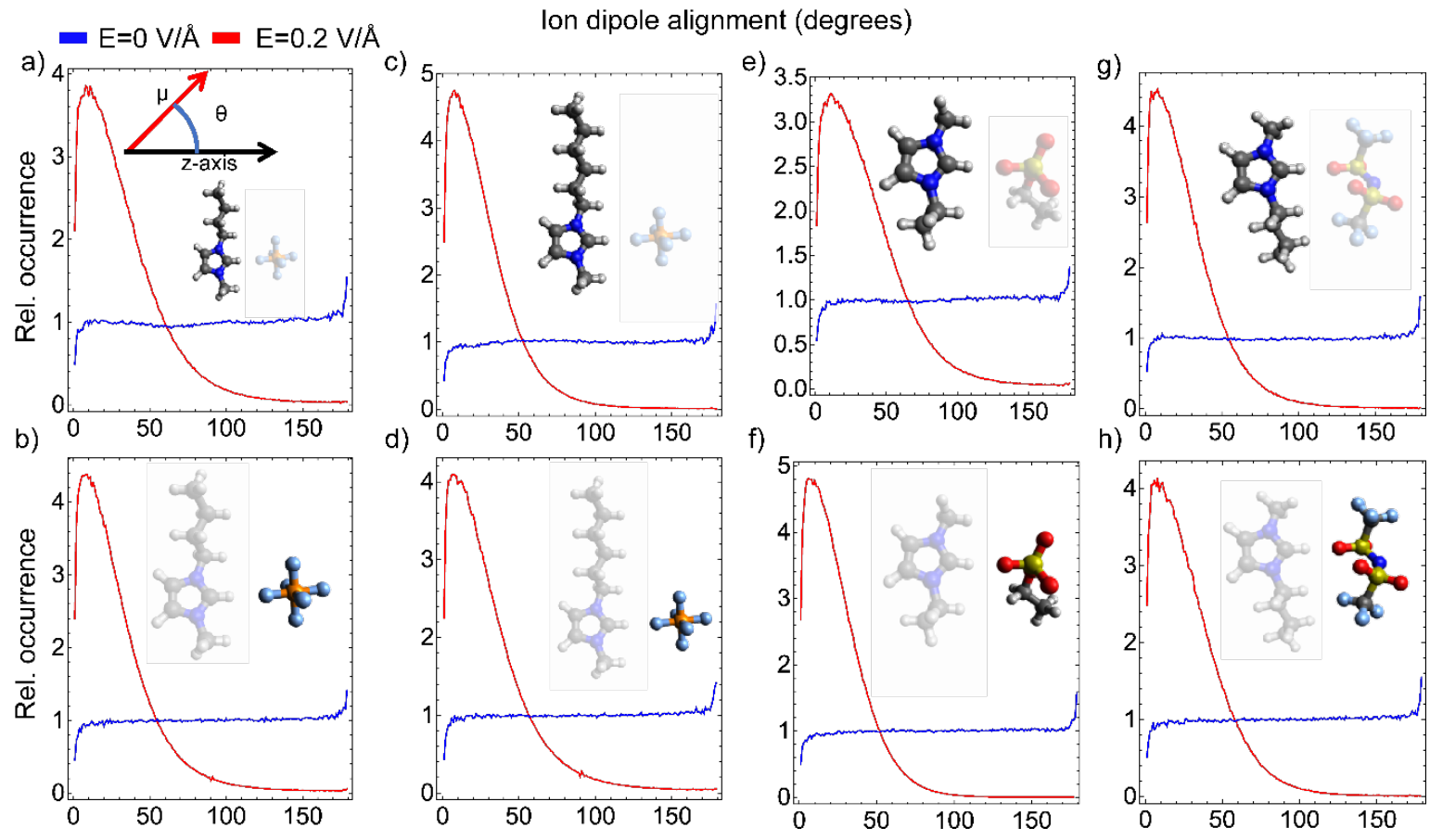

Figure S15. Cone-corrected angular distributions ion dipoles relative to the z-axis of (a) $\mathrm{BMIM}^{+}$and (b) $\mathrm{PF}_{6}{ }^{-}$in $\left[\mathrm{BMIM}\left[\mathrm{PF}_{6}\right]\right.$, (c) $\mathrm{HMIM}^{+}$and (d) $\mathrm{PF}_{6}{ }^{-}$in $\left[\mathrm{HMIM}\left[\mathrm{PF}_{6}\right]\right.$, (e) $\mathrm{EMIM}^{+}$ and (f) $\mathrm{EtSO}_{4}{ }^{-}$in $[\mathrm{EMIM}]\left[\mathrm{EtSO}_{4}\right]$ and (g) $\mathrm{BMIM}^{+}$and (h) $\mathrm{NTf}_{2}{ }^{-}$in $[\mathrm{BMIM}]\left[\mathrm{NTf}_{2}\right]$. 


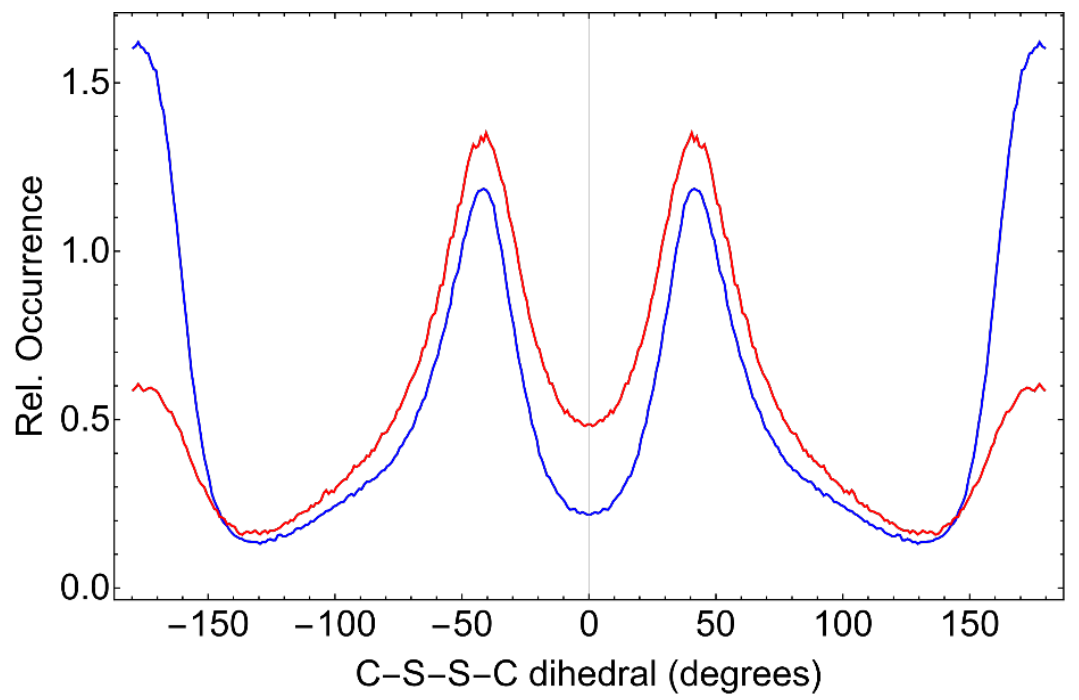

Figure S16. Dihedral distribution function of the $\mathrm{C}-\mathrm{S}-\mathrm{S}-\mathrm{C}$ dihedral in $\mathrm{NTf}_{2}^{-}$across simulations in the absence of an electric field (blue) and in a $0.2 \mathrm{~V} / \AA$ external electric field (red). 


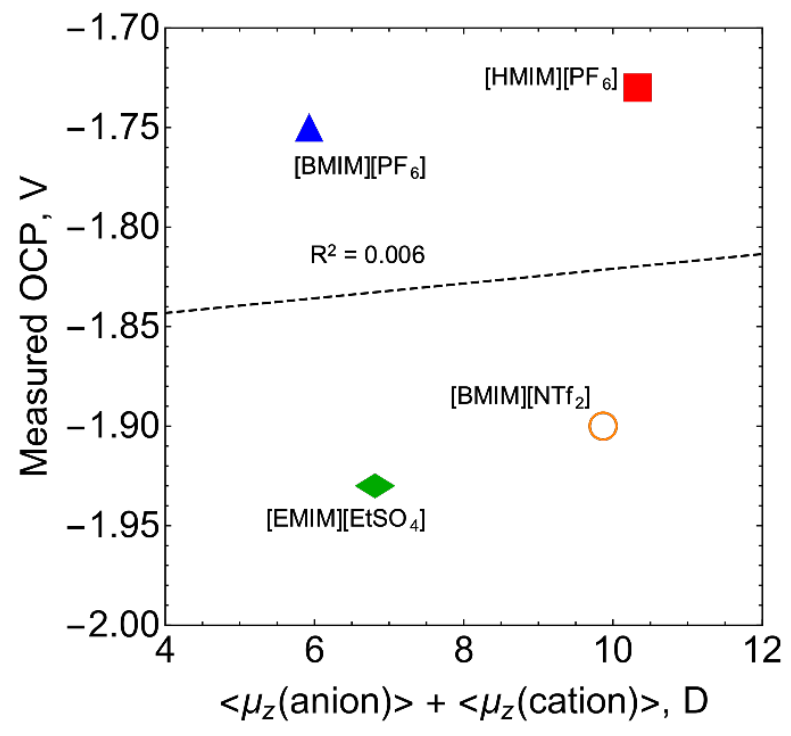

Figure S17. Plot of the sum of the mean dipole projection of constituent ions against the

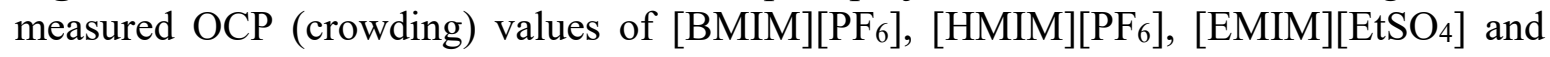
$[\mathrm{BMIM}]\left[\mathrm{NTf}_{2}\right]$. 


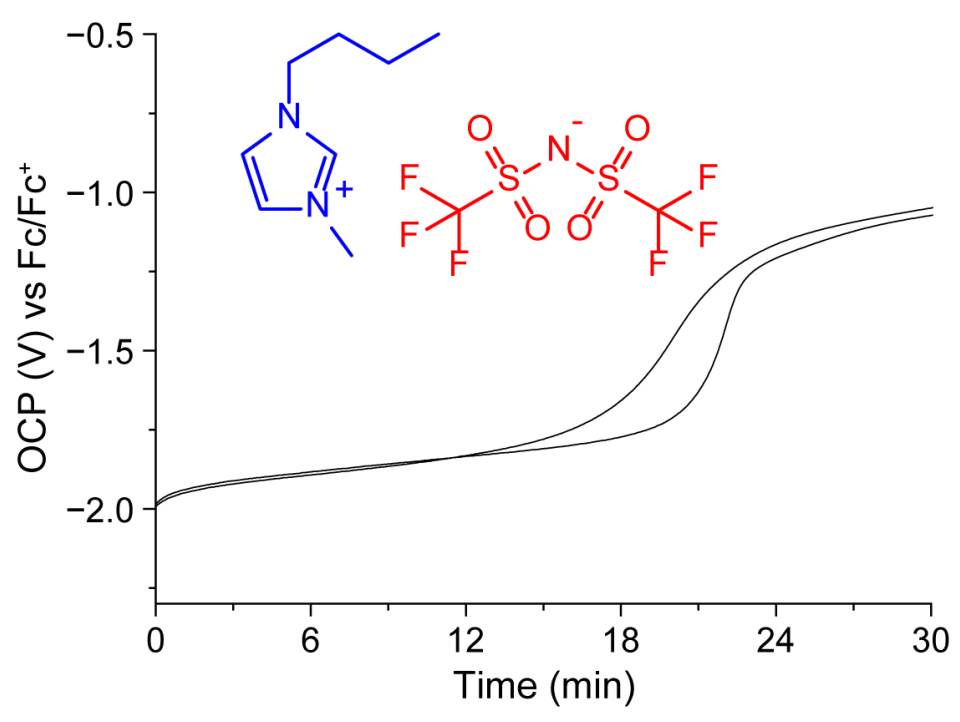

Figure S18. Representative OCP-time measurements acquired with platinum electrodes immersed in [BMIM] $\left.\mathrm{NTf}_{2}\right]$ immediately after a negative potential step $(60 \mathrm{~s})$. The potential step was of $-2.0 \mathrm{~V}$ relative to the electrode initial rest OCP. The crowding plateau in $[\mathrm{BMIM}]\left[\mathrm{NTf}_{2}\right]$ is found at $-1.9 \mathrm{~V}$. 

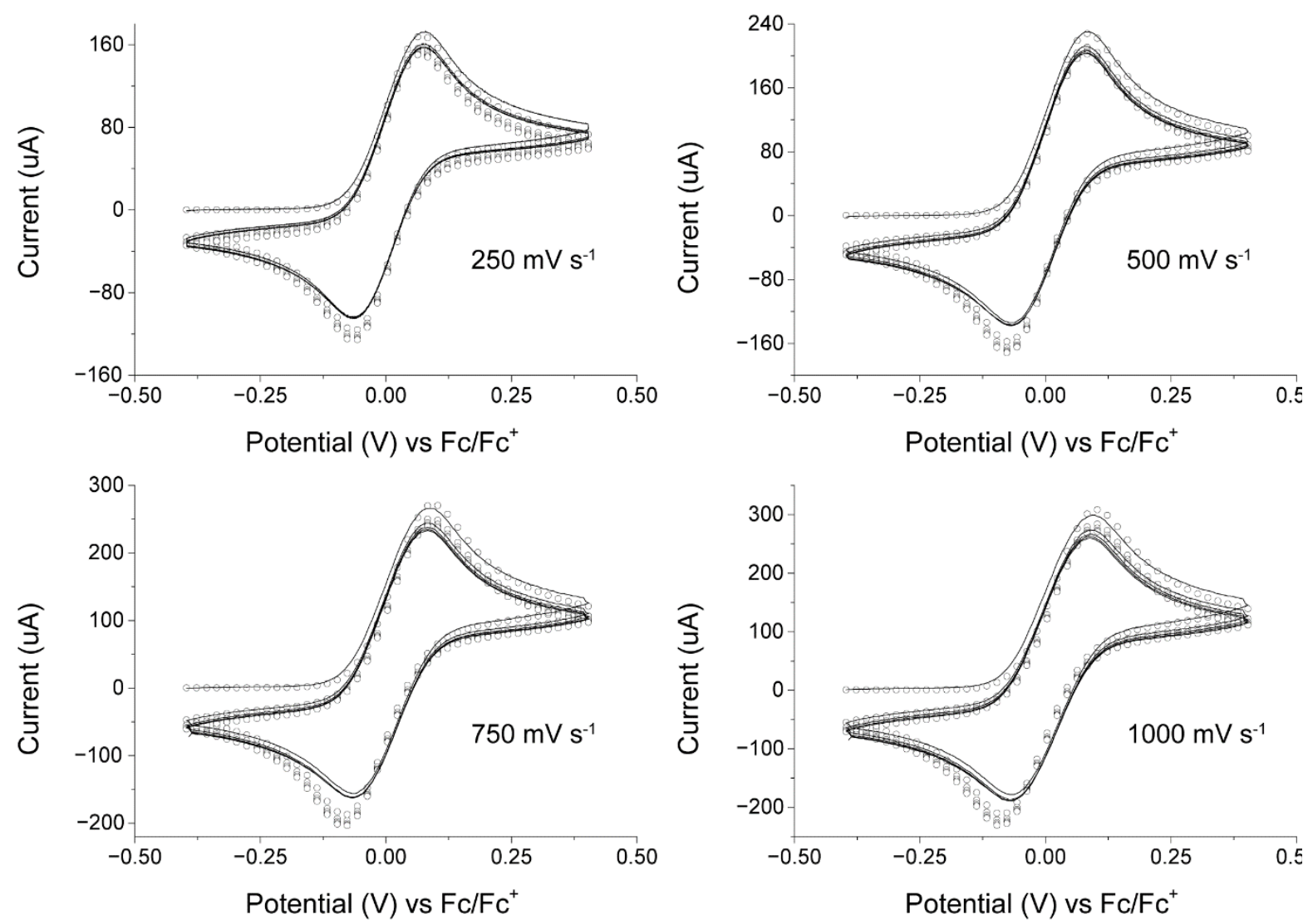

Figure S19. Experimental (solid line) and simulated (empty symbols) cyclic voltammograms at a platinum wire in an acetonitrile solution containing $1.0 \times 10^{-3} \mathrm{M}$ ferrocene and $1.0 \times 10^{-1} \mathrm{Bu}_{4} \mathrm{NClO}_{4}$. The voltage sweep rate is indicated as labels to the figures. The diffusivity of ferrocene ( $\mathrm{Fc}$ in shorthand) was set to $2.3 \times 10^{-5} \mathrm{~cm}^{2} \mathrm{~s}^{-1}$. The refined parameters (E mechanism) are: $E^{0}\left(\mathrm{Fc} / \mathrm{Fc}^{+}\right)=0.597 \mathrm{~V}$ vs. $\mathrm{Ag} / \mathrm{AgCl}$ ("leakless", see experimental section), $k^{0}\left(\mathrm{Fc} / \mathrm{Fc}^{+}\right)=0.01 \mathrm{~cm} \mathrm{~s}^{-1}, \alpha=0.5$. The cell iR drop was not compensated during measurement. Values of cell resistance used in the fittings were measured by electrochemical impedance spectroscopy prior to the experiment and used in the simulations. Butler-Volmer kinetics was used to estimate charge transfer parameters, and the diffusion was considered as semi-infinite 1D. The electrochemically-determined effective area of the platinum wire electrode is $0.28 \mathrm{~cm}^{2}$. 

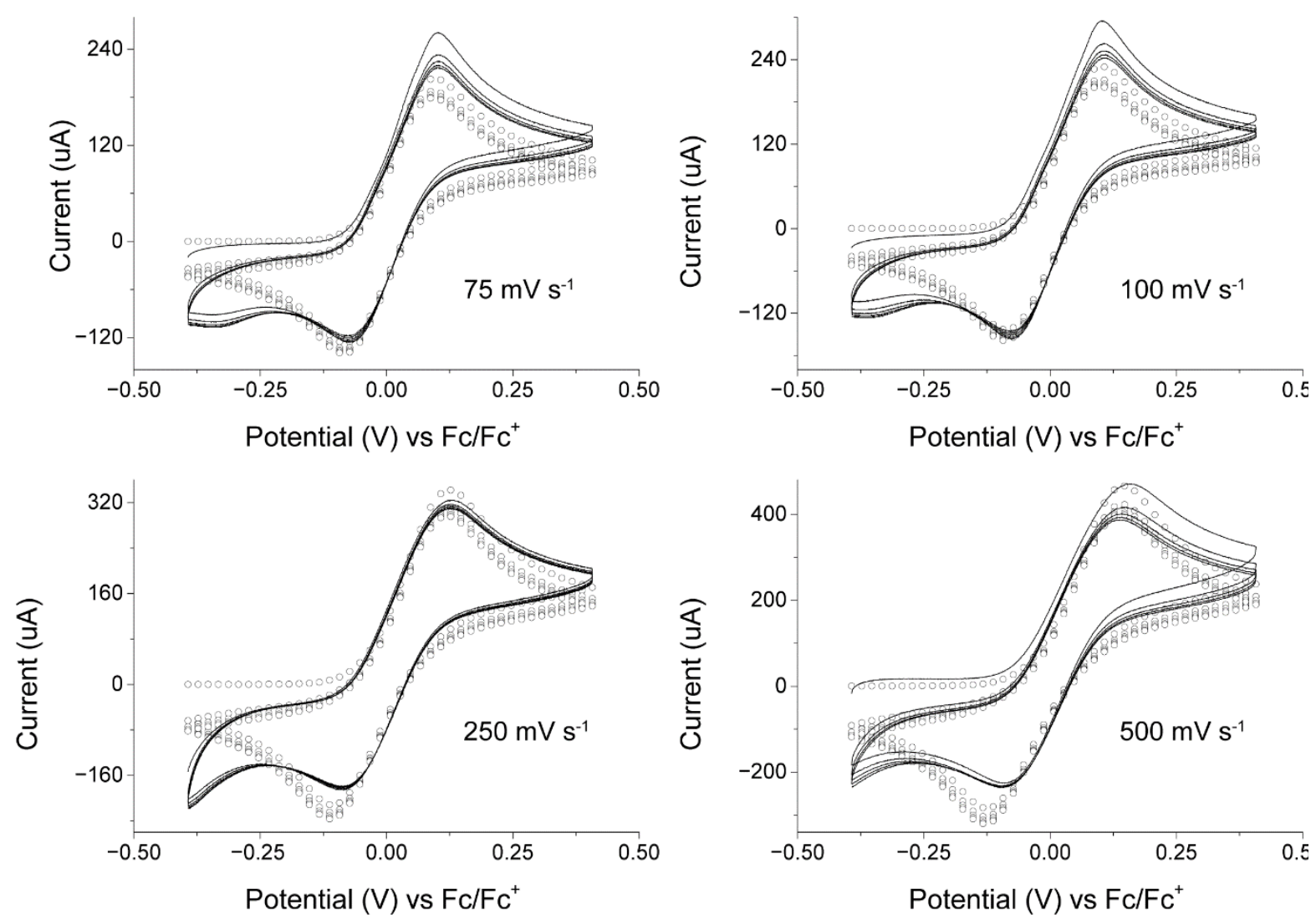

Figure S20. Experimental (solid line) and simulated (empty symbols) cyclic voltammograms at a platinum wire in an acetonitrile solution containing $1.0 \times 10^{-3} \mathrm{M}$ ferrocene and $1.0 \times 10^{-1} \mathrm{Bu}_{4} \mathrm{NClO}_{4}$. The voltage sweep rate is indicated as labels to the figures. The diffusivity of ferrocene ( $\mathrm{Fc}$ in shorthand) was set to $2.3 \times 10^{-5} \mathrm{~cm}^{2} \mathrm{~s}^{-1}$. The refined parameters (E mechanism) are: $E^{0}\left(\mathrm{Fc} / \mathrm{Fc}^{+}\right)=0.592 \mathrm{~V}$ vs. $\mathrm{Ag} / \mathrm{AgCl}$ ("leakless", see experimental section), $k^{0}\left(\mathrm{Fc} / \mathrm{Fc}^{+}\right)=0.01 \mathrm{~cm} \mathrm{~s}^{-1}, \alpha=0.5$. The cell iR drop was not compensated during measurement. Values of cell resistance used in the fittings were measured by electrochemical impedance spectroscopy prior to the experiment and used in the simulations. Butler-Volmer kinetics was used to estimate charge transfer parameters, and the diffusion was considered as semi-infinite 1D. The electrochemically-determined effective area of the platinum wire electrode is $0.63 \mathrm{~cm}^{2}$. 

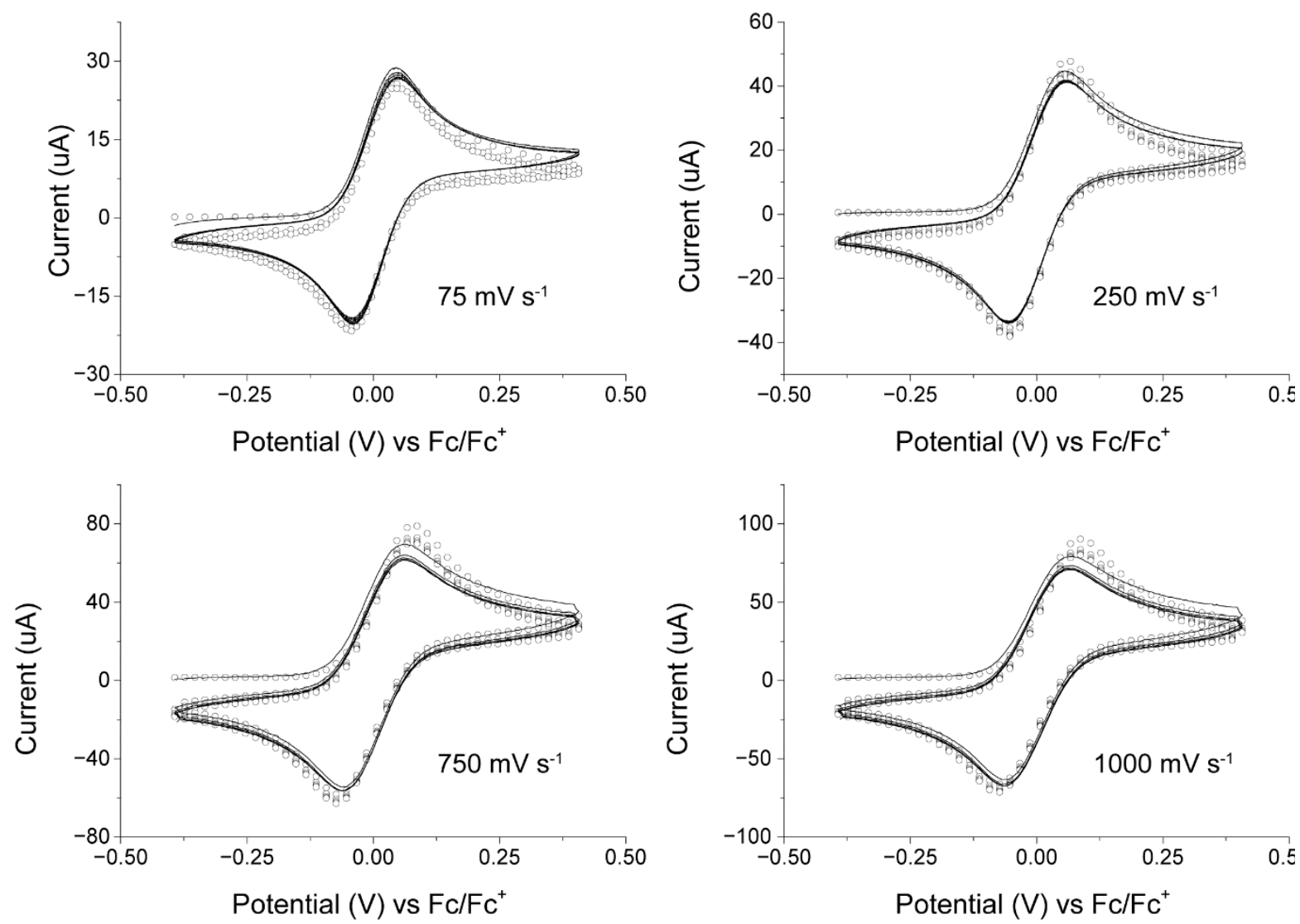

Figure S21. Experimental (solid line) and simulated (empty symbols) cyclic voltammograms at a platinum disk in an acetonitrile solution containing $1.0 \times 10^{-3} \mathrm{M}$ ferrocene and $1.0 \times 10^{-1} \mathrm{Bu}_{4} \mathrm{NClO}_{4}$. The voltage sweep rate is indicated as labels to the figures. The diffusivity of ferrocene ( $\mathrm{Fc}$ in shorthand) was set to $2.3 \times 10^{-5} \mathrm{~cm}^{2} \mathrm{~s}^{-1}$. The refined parameters (E mechanism) are: $E^{0}\left(\mathrm{Fc} / \mathrm{Fc}^{+}\right)=0.593 \mathrm{~V}$ vs. $\mathrm{Ag} / \mathrm{AgCl}$ ("leakless", see experimental section), $k^{0}\left(\mathrm{Fc} / \mathrm{Fc}^{+}\right)=0.01 \mathrm{~cm} \mathrm{~s}^{-1}, \alpha=0.5$. The cell $\mathrm{iR}$ drop was not compensated during measurement. Values of cell resistance used in the fittings were measured by electrochemical impedance spectroscopy prior to the experiment and used in the simulations. Butler-Volmer kinetics was used to estimate charge transfer parameters, and the diffusion was considered as semi-infinite 2D. The electrochemically-determined effective area of the platinum disk electrode is $0.08 \mathrm{~cm}^{2}$. 


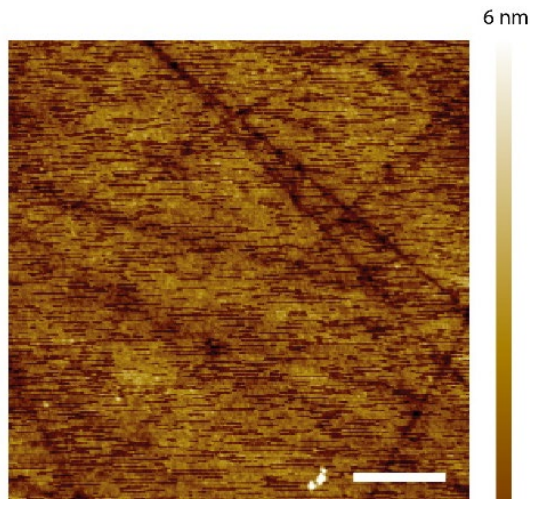

Figure S22. Representative AFM topography (height) image $(5 \times 5 \mu \mathrm{m})$ of a glassy carbon electrode. The scale bar at bottom right represents $1 \mu \mathrm{m}$. Using the region analysis function in the image processing software XEI (Park System Corporation), the root-mean-square (RMS) roughness of the sample surface was estimated to $1.365 \mathrm{~nm}$.

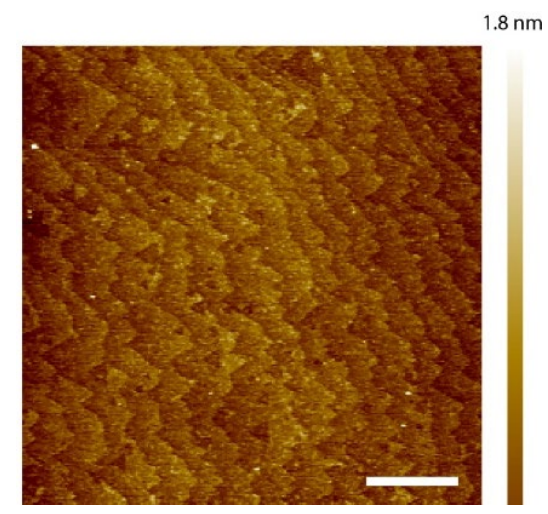

Figure S23. Representative AFM topography (height) image $(5 \times 5 \mu \mathrm{m})$ of a monolayer-coated silicon electrode. The scale bar at bottom right represents $1 \mu \mathrm{m}$. The silicon was highly doped (phosphorous, 0.007-0.013 ohm cm), n-type hydrogen-terminated Si(111) coated with a Si-Cbound monolayer of 1,8-nonadiyne. The clear terraced structure and the negligible amount of rounded features indicates an exceedingly low level of substrate oxidation. The root-meansquare (RMS) roughness of the sample is $0.301 \mathrm{~nm}$ (XEI software, Park System Corporation). 
a)

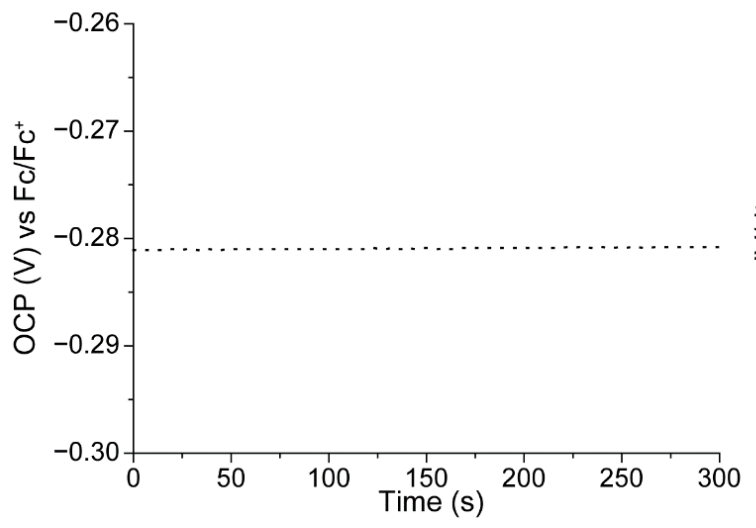

b)

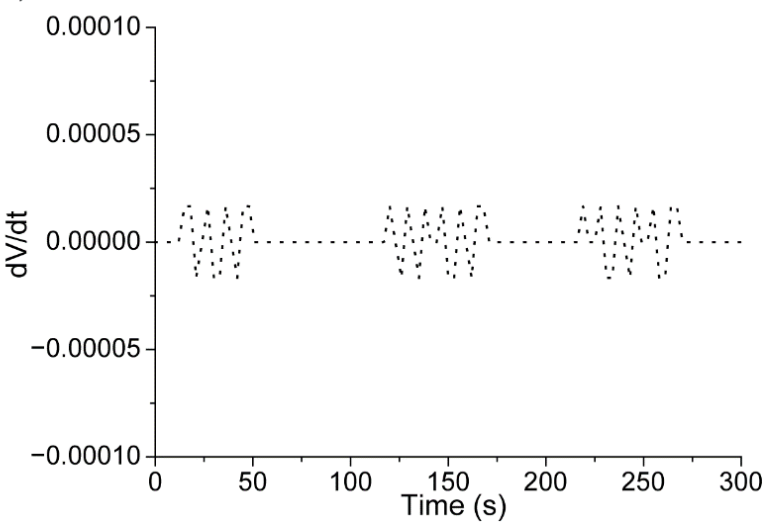

Figure S24. Prior to any external biasing, electrodes were left to equilibrate in contact with the ionic liquid sample until the first derivative of the OCP versus time trace $(\mathrm{dV} / \mathrm{dt})$ felt below $|0.0001|$. (a) Example of initial equilibration of the OCP for a platinum electrode immersed in [EMIM] [EtSO 4$]$, and its first derivative shown in (b). 
a)

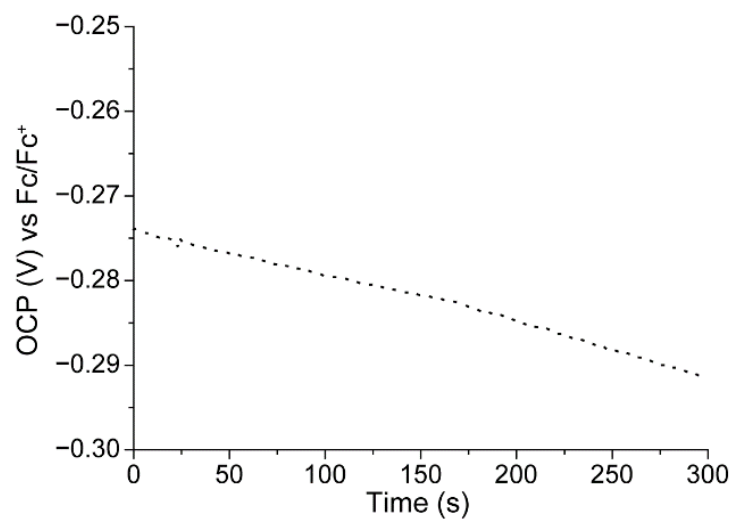

b)

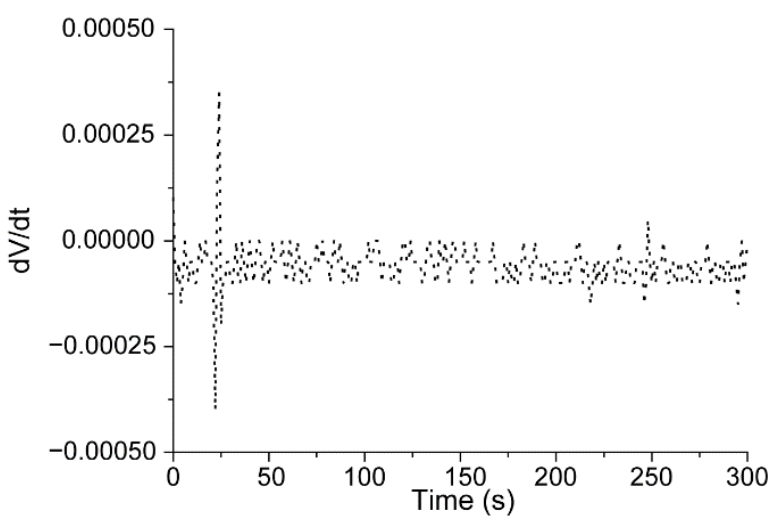

Figure S25. (a) Representative initial OCP-time measurement acquired with a platinum electrode immersed in [BMIM] $\left[\mathrm{PF}_{6}\right]$, and its first derivative (b). Prior to any external bias being applied to the interface, electrodes were left to equilibrate in contact with the ionic liquid sample until the first derivative of the OCP versus time trace $(\mathrm{dV} / \mathrm{dt})$ dropped below $|0.0001|$. 
a)

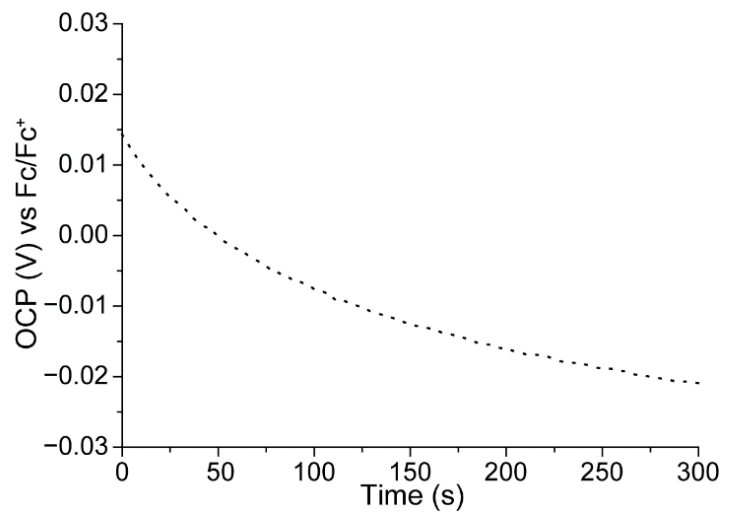

b)

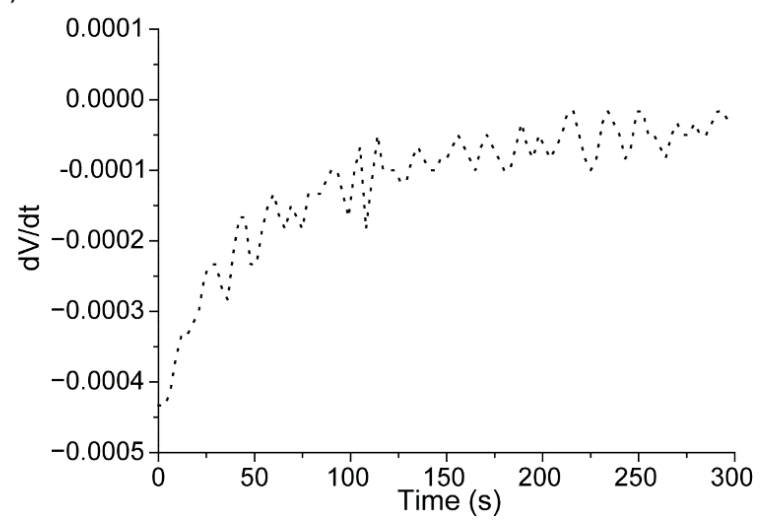

Figure S26. Example of initial OCP-time measurements acquired with a platinum electrode immersed in [HMIM] $\left[\mathrm{PF}_{6}\right]$ (a) and its first derivative (b). Prior to any external bias being applied to the interface, electrodes were left to equilibrate in contact with the ionic liquid sample until the first derivative of the OCP versus time trace $(\mathrm{dV} / \mathrm{dt})$ dropped below $|0.0001|$. 
a)

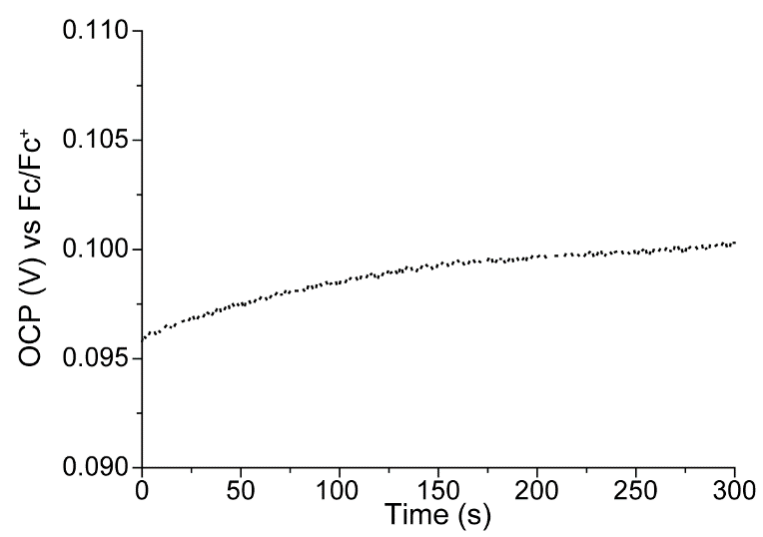

b)

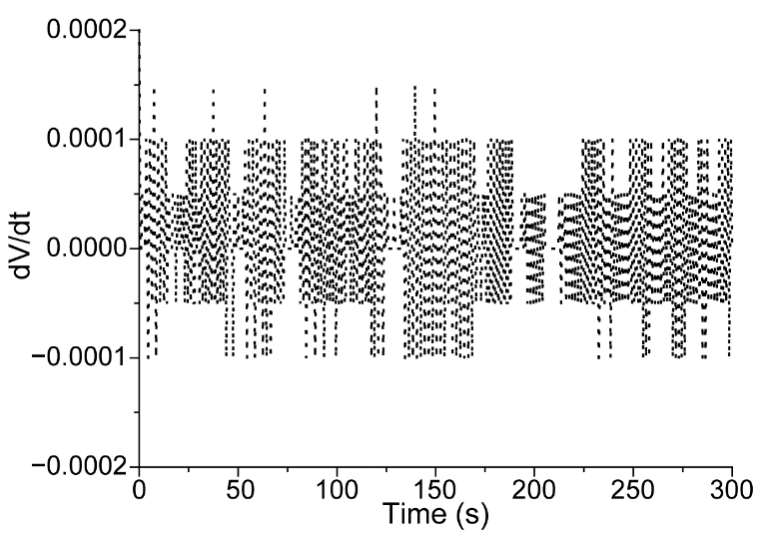

Figure S27. Example of initial OCP-time measurement acquired with a platinum electrode immersed in [ $\left.\mathrm{P}_{1466}\right]\left[\mathrm{NTf}_{2}\right]$ (a) and its first derivative (b). Electrodes were left to equilibrate in contact with the ionic liquid sample until the first derivative of the OCP versus time traces $(\mathrm{dV} / \mathrm{dt})$ dropped below $|0.0001|$. 


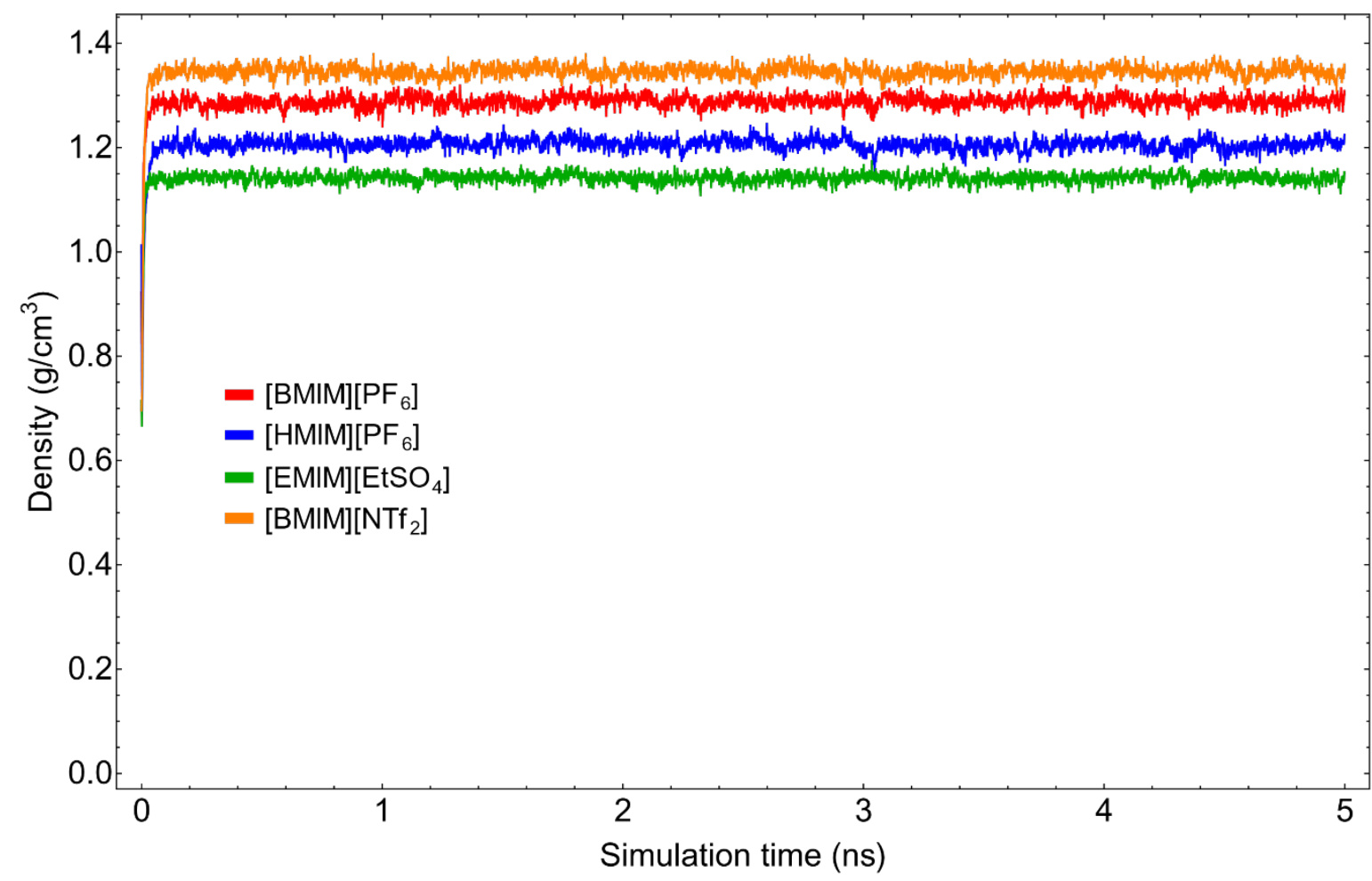

Figure S28. Evolution of density over time in equilibration molecular simulation runs of $[\mathrm{BMIM}]\left[\mathrm{PF}_{6}\right]$ (red), [HMIM][PF6] (blue), [EMIM][EtSO $]$ (green) and [BMIM][NTf $]$ (orange). 
Table S1. $k_{i j}$ parameters calculated for this work. Minimum energy configurations were obtained from a thorough geometry search of possible starting configurations subject to M062X/cc-pVTZ calculations, with implicit ethanol solvation represented with the CPCM model. ${ }^{1}$ Frequency analysis confirmed local minima of minimum energy structures, determined by SRS-MP2 $2^{2-3}$ single point energy calculations. Minimum energy structures were subject to SAPT2+/aug-cc-pVDZ ${ }^{4}$ calculations to determine $k_{i j}$ parameters. All frequency and geometry optimisations were performed with GAUSSIAN16a03, ${ }^{5}$ with SAPT2+ and single point calculations performed with PSI $4 .^{6}$

\begin{tabular}{cc}
\hline Interacting pair & $\boldsymbol{k}_{i j}$ value \\
\hline $\mathbf{E M I M}^{+}-\mathbf{P F}_{6}{ }^{-}$ & 0.55 \\
\hline EMIM $^{+}-\mathbf{E t S O}_{4}{ }^{-}$ & 0.52 \\
\hline $\mathbf{P F}_{6}{ }^{-}-\mathbf{C}_{4} \mathbf{H}_{10}$ & 0.57 \\
\hline $\mathbf{P F}_{6}{ }^{-} \mathbf{C}_{6} \mathbf{H}_{\mathbf{1 4}}$ & 0.58
\end{tabular}

Table S2. Comparison of equilibrated densities from molecular dynamics simulations to literature.

\begin{tabular}{|c|c|c|c|}
\hline Ionic liquid & $\rho^{e x p} \mathbf{g} / \mathbf{c m}^{3}$ & $\rho^{s i m} \mathrm{~g} / \mathrm{cm}^{3}$ & $\%$ dev. \\
\hline$[\mathrm{BMIM}]\left[\mathrm{PF}_{6}\right]$ & $1.323^{7}$ & 1.288 & -2.6 \\
\hline$\left[\mathrm{HMIM}_{[}\left[\mathrm{PF}_{6}\right]\right.$ & $1.251^{8}$ & 1.204 & -3.8 \\
\hline$\left[\right.$ EMIM] $\left[\mathrm{EtSO}_{4}\right]$ & $1.201^{9}$ & 1.142 & -4.9 \\
\hline$\left[\mathrm{BMIM}\left[\mathrm{NTf}_{2}\right]\right.$ & $1.386^{10}$ & 1.346 & -2.9 \\
\hline
\end{tabular}

Table S3. Observed diffusion coefficients of ions in production simulations, in the absence of an external electric field

\begin{tabular}{|c|c|c|}
\hline Ionic liquid & $\begin{array}{c}\mathrm{D}(\text { cation }) \times 10^{11} \\
\mathrm{~m}^{2} / \mathrm{s}\end{array}$ & $D($ anion $) \times 10^{11} \mathrm{~m}^{2} / \mathrm{s}$ \\
\hline$[\mathrm{BMIM}]\left[\mathrm{PF}_{6}\right]$ & 12.2 & 9.6 \\
\hline [HMIM][PF & 3.7 & 4.7 \\
\hline$[\mathrm{EMIM}]\left[\mathrm{EtSO}_{4}\right]$ & 14.9 & 10.2 \\
\hline$[\mathbf{B M I M}]\left[\mathbf{N T f}_{2}\right]$ & 17.6 & 16.6 \\
\hline
\end{tabular}


Table S4. Observed diffusion coefficients of ions in production simulations, in an external electric field of $0.2 \mathrm{~V} / \AA$

\begin{tabular}{ccc}
\hline Ionic liquid & D(cation) $\times \mathbf{1 0}^{\mathbf{7}} \mathbf{~ m}^{\mathbf{2}} \mathbf{s}$ & $\mathbf{D}($ anion $) \times \mathbf{1 0}^{\mathbf{7}} \mathbf{~ m}^{\mathbf{2}} \mathbf{s}$ \\
\hline$\left[\mathbf{B M I M}_{[}\left[\mathbf{P F}_{\mathbf{6}}\right]\right.$ & 24.5 & 22.6 \\
\hline$\left[\mathrm{HMIM}_{[}\left[\mathbf{P F}_{\mathbf{6}}\right]\right.$ & 22.2 & 29.6 \\
\hline$[\mathbf{E M I M}]\left[\mathbf{E t S O}_{4}\right]$ & 16.6 & 17.2 \\
\hline$[\mathrm{BMIM}]\left[\mathbf{N T f}_{\mathbf{2}}\right]$ & 15.0 & 3.7 \\
\hline
\end{tabular}

Table S5. Calculated molar volumes of cations using HF/aug-cc-pVTZ electron densities ${ }^{11}$

\begin{tabular}{cc}
\hline Cation & $\mathbf{V}_{\mathbf{m}}(\AA)$ \\
\hline BMIM $^{+}$ & 185.5 \\
\hline HMIM $^{+}$ & 246.7 \\
\hline
\end{tabular}




\section{S2. References}

(1) Low, K.; Tan, S. Y. S.; Izgorodina, E. I., An ab initio Study of the Structure and Energetics of Hydrogen Bonding in Ionic Liquids. Front. Chem. 2019, 7.

(2) Tan, S.; Barrera Acevedo, S.; Izgorodina, E. I., Generalized spin-ratio scaled MP2 method for accurate prediction of intermolecular interactions for neutral and ionic species. $J$. Chem. Phys. 2017, 146 (6), 064108.

(3) Tan, S. Y. S.; Wylie, L.; Begic, I.; Tran, D.; Izgorodina, E. I., Application of spin-ratio scaled MP2 for the prediction of intermolecular interactions in chemical systems. Phys. Chem. Chem. Phys. 2017, 19 (42), 28936-28942.

(4) Goloviznina, K.; Canongia Lopes, J. N.; Costa Gomes, M.; Pádua, A. A. H., Transferable, Polarizable Force Field for Ionic Liquids. J. Chem. Theory Comput. 2019, 15 (11), 5858-5871.

(5) Frisch, M. J.; Trucks, G. W.; Schlegel, H. B.; Scuseria, G. E.; Robb, M. A.; Cheeseman, J. R.; Scalmani, G.; Barone, V.; Petersson, G. A.; Nakatsuji, H.; Li, X.; Caricato, M.; Marenich, A. V.; Bloino, J.; Janesko, B. G.; Gomperts, R.; Mennucci, B.; Hratchian, H. P.; Ortiz, J. V.; Izmaylov, A. F.; Sonnenberg, J. L.; Williams; Ding, F.; Lipparini, F.; Egidi, F.; Goings, J.; Peng, B.; Petrone, A.; Henderson, T.; Ranasinghe, D.; Zakrzewski, V. G.; Gao, J.; Rega, N.; Zheng, G.; Liang, W.; Hada, M.; Ehara, M.; Toyota, K.; Fukuda, R.; Hasegawa, J.; Ishida, M.; Nakajima, T.; Honda, Y.; Kitao, O.; Nakai, H.; Vreven, T.; Throssell, K.; Montgomery Jr., J. A.; Peralta, J. E.; Ogliaro, F.; Bearpark, M. J.; Heyd, J. J.; Brothers, E. N.; Kudin, K. N.; Staroverov, V. N.; Keith, T. A.; Kobayashi, R.; Normand, J.; Raghavachari, K.; Rendell, A. P.; Burant, J. C.; Iyengar, S. S.; Tomasi, J.; Cossi, M.; Millam, J. M.; Klene, M.; Adamo, C.; Cammi, R.; Ochterski, J. W.; Martin, R. L.; Morokuma, K.; Farkas, O.; Foresman, J. B.; Fox, D. J. Gaussian 16 Rev. A.03, Wallingford, CT, 2016.

(6) Smith, D. G. A.; Burns, L. A.; Simmonett, A. C.; Parrish, R. M.; Schieber, M. C.; Galvelis, R.; Kraus, P.; Kruse, H.; Di Remigio, R.; Alenaizan, A.; James, A. M.; Lehtola, S.; Misiewicz, J. P.; Scheurer, M.; Shaw, R. A.; Schriber, J. B.; Xie, Y.; Glick, Z. L.; Sirianni, D. A.; O’Brien, J. S.; Waldrop, J. M.; Kumar, A.; Hohenstein, E. G.; Pritchard, B. P.; Brooks, B. R.; Schaefer, H. F.; Sokolov, A. Y.; Patkowski, K.; DePrince, A. E.; Bozkaya, U.; King, R. A.; Evangelista, F. A.; Turney, J. M.; Crawford, T. D.; Sherrill, C. D., PSI4 1.4: Open-source software for highthroughput quantum chemistry. J. Chem. Phys. 2020, 152 (18), 184108.

(7) Rocha, M. A. A.; Ribeiro, F. M. S.; Ferreira, A. I. M. C. L.; Coutinho, J. A. P.; Santos, L. M. N. B. F., Thermophysical properties of [CN-1C1im][PF6] ionic liquids. J. Mol. Liq.

(8) Li, J.-G.; Hu, Y.-F.; Ling, S.; Zhang, J.-Z., Physicochemical Properties of [C6mim][PF6] and [C6mim][(C2F5)3PF3] Ionic Liquids. J. Chem. Eng. Data 2011, 56 (7), 3068-3072.

(9) Fernández, A.; Torrecilla, J. S.; García, J.; Rodríguez, F., Thermophysical Properties of 1Ethyl-3-methylimidazolium Ethylsulfate and 1-Butyl-3-methylimidazolium Methylsulfate Ionic Liquids. J. Chem. Eng. Data 2007, 52 (5), 1979-1983.

(10) Tomida, D.; Kanno, S.; Qiao, K.; Yokoyama, C., Viscosities at pressures up to $20 \mathrm{MPa}$ and thermal conductivities at $0.1 \mathrm{MPa}$ of 1-alkyl-3-methylimidazolium bis [(trifluoromethyl) sulfonyl] amides. High Temp. - High Pressures 2017, 46 (3).

(11) Izgorodina, E. I.; Forsyth, M.; MacFarlane, D. R., On the components of the dielectric constants of ionic liquids: ionic polarization? Phys. Chem. Chem. Phys. 2009, 11 (14), 24522458 . 